Document downloaded from:

http://hdl.handle.net/10251/157358

This paper must be cited as:

Domenech Carbo, MT.; Alvarez-Romero, C.; Doménech Carbó, A.; Osete Cortina, L.; Martínez Bazán, ML. (2019). Microchemical surface analysis of historic copper-based coins by the combined use of FIB-FESEM-EDX, OM, FTIR spectroscopy and solid-state electrochemical techniques. Microchemical Journal. 148:573-581.

https://doi.org/10.1016/j.microc.2019.05.039

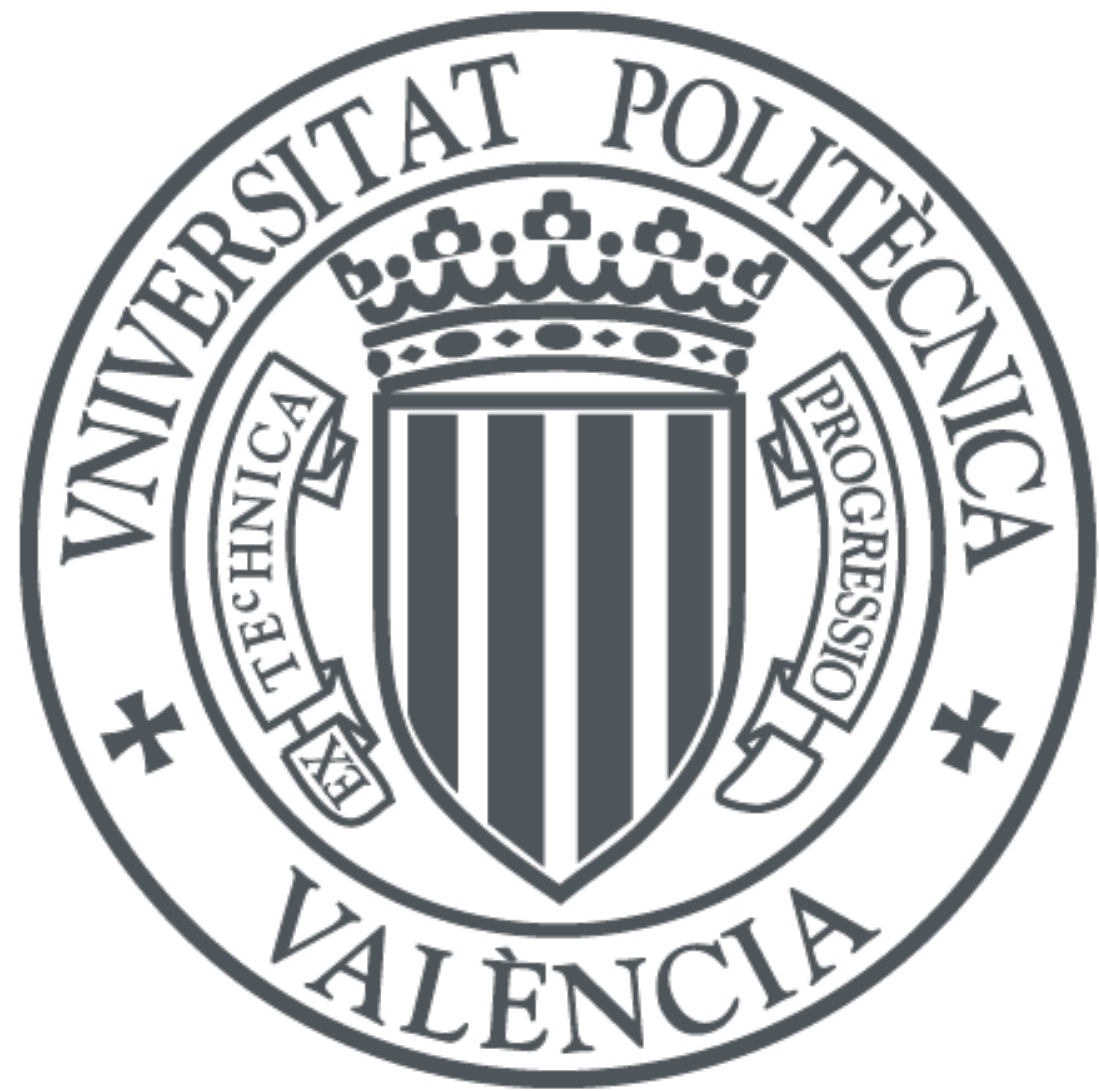

The final publication is available at

https://doi.org/10.1016/j.microc.2019.05.039

Copyright Elsevier

Additional Information 


\title{
Microchemical surface analysis of historic copper-based coins by the combined use of FIB-FESEM-EDX, OM, FTIR spectroscopy and solid-state electrochemical techniques
}

María Teresa Doménech-Carbóa ${ }^{\mathrm{a}^{*}}$, Carla Álvarez-Romero ${ }^{\mathrm{a}}$, Antonio Doménech-Carbób, Laura Osete-Cortina ${ }^{\mathrm{a}}$, María Luisa Martínez-Bazán ${ }^{\mathrm{a}}$

${ }^{a}$ Institut de Restauració del Patrimoni, Universitat Politècnica de València, Camí de Vera 14, 46022, València, Spain.

${ }^{b}$ Departament de Química Analítica. Universitat de València. Dr. Moliner, 50, 46100 Burjassot (València) Spain.

* Corresponding author; e-mail: tdomenec@crbc.upv.es

\begin{abstract}
A multi-technique strategy, including microscopy, spectroscopic and electrochemical techniques, is proposed to study thin corrosion layers that form on the surface of historic copper-based coins. An accurate characterisation of this external corrosion layer is important for selecting a suitable conservation and/or restoration treatment. For this purpose, a series of copper-based coins from different historical periods and provenances, which mainly exhibited atmospheric corrosion, was analysed. The morphology of the corrosion layer and the upper core of coins was studied in trenches done on coin surfaces with a focused ion beam gun, coupled to a field emission scanning electron microscopeX-ray microanalysis (FIB-FESEM-EDX). The X-ray microanalysis performed with FESEM-EDX on trenches allowed elemental composition profiles on the corrosion layer to be obtained. These results were complemented with the compositional data of the corrosion products provided by the voltammetry of immobilised microparticles (VIMP) and Fourier transform infrared spectroscopy (FTIR), and by studying visual appearance by optical microscopy and colorimetry. Cuprite and tenorite (the latter increased with coin age) were the main identified corrosion products, which were accompanied, to a lesser extent, by copper trihydroxychloride polymorphs. Interestingly, metal oxalates and metalcarboxylate complexes were identified on the corrosion layer of most coins. These unusual alteration products of copper-based coins were formed from the organic matter deposited on coin surfaces given their use when placed in circulation or by further manipulations of collectors.
\end{abstract}

Keywords: FIB-FESEM-EDX, FTIR spectroscopy, voltammetry of microparticles, corrosion products, coin, heritage conservation. 


\section{Introduction}

Coins constitute an important type of metal heritage artefacts and provide abundant information on civilisations from antiquity to modern times. In parallel to archaeological studies, archaeometrical and archaeometallurgical ones focus on characterising metal composition and correlating it with a manufacture technique, historic period and geographical distribution. Compositional studies are particularly interesting because they are conducted to identify a coin's alloy composition in connection to the relative chronology between different emissions [1] and to the efforts of rulers during all historic periods to reduce fraudulent monetary production by properly modifying alloy compositions [2]. Archaeometrical studies can also probe the application of specific minting techniques, such as plating [3], to produce forgeries [4], and to also reduce costs while producing official money during periods of crisis. Examples of this last practice can be found in the Roman Republic in the production of nummi (308-311 A.D.) at Carthago [5] during the Roman Imperial period in the production of Antoninians introduced by Caracalla (Marcus Aurelius Antoninus Pius) in 215 A.D [6], or in Renaissance coins minted in Gubbio (Italy) [7].

Besides this variety of archaeometrical studies, scientific examinations of historic and archaeological artifacts are normally carried out to recognise the corrosion processes that affect coins to determine the composition and morphology of corrosion layers or patinas, and to thus enable to establish the most suitable conservation treatment. Analytical studies of corrosion patinas on copper-based coins and other artifacts are based on a wide variety of instrumental techniques, including Atomic Absorption Spectroscopy (AAS), X-ray Fluorescence and Microfluorescence (XRF, $\mu$-XRF), Inductively Coupled Plasma-Atomic Emission or Mass Spectroscopy (ICP-AES, ICPMS), Laser Ablation ICP-MS (LA-ICP-MS), Proton Induced X-ray Emission (PIXE, $\mu-$ PIXE), micro-X-ray Diffraction ( $\mu$-XRD), X-ray Photoelectron Spectroscopy (XPS), Scanning Electron Microscopy-X-ray Microanalysis (SEM-EDX), Optical Microscopy (OM), $\mu$-Raman Spectroscopy, Fourier Transform Infrared Spectroscopy (FTIR), Laser Induced Breakdown Spectroscopy (LIBS), Deep Protons Activation Analysis (DPAA), Gamma ray Transmission (GRT) or Neutron Diffraction Analysis, among others [8-20].

The present research aimed to develop a multi-technique strategy to perform a surface analysis of the patinas formed from both environmental corrosion mechanisms and the deterioration of coins when placed in circulation. The selected instrumental techniques included Field Emission Scanning Electron Microscopy-X-ray microanalysis (FESEMEDX) coupled with focused ion beam (FIB), voltammetry of immobilised microparticles (VIMP), FTIR spectroscopy, OM and colorimetry. These techniques enable the identification of inorganic and organic corrosion products that form patinas, as well as sporadic elemental composition and deep profiles along corrosion layers. FTIR identifies organic compounds. In particular, FESEM-EDX provides morphological data, elemental compositions and deep profiles on trenches performed 
with FIB [6]. The combination of both techniques enables a nanoinvasive method as the loss of matter in trenches is of only a few ng. VIMP enables the characterisation of the inorganic corrosion products present in patinas. The latter, developed by Scholz et al [21-23], is a solid-state electrochemistry technique that allows small samples to be analysed within the nanogram range and is, therefore, barely invasive. This technique has been applied to analyse the corrosion patinas of buried bronze artifacts [24-31]. Dating [32-34] and mint discrimination studies [2,35] have also been developed with this solid-state electrochemical technique. The proposed analytical strategy was applied to study a series of copper-based coins with different compositions and provenances in Europe that date back to the period from 1709 to 1924.

\section{Materials and Methods}

\subsection{Description of coins}

One first important criterion in this work is based on the selection of the studied coins. The specialised literature on the scientific study of coins focuses mainly on the corrosion patinas of old coins conserved in burial and submarine environments as they present severe alteration problems. Very few studies have characterised the effects of alterations due to the use of coins when placed in circulation or were simply exposed to atmospheric conditions. The study conducted herein demonstrated that some processes have not been described in the literature to date and take place due to the interaction of the organic matter deposited on coins in circulation and the ions that form electrochemicaly on the surface and subsurface owing to common corrosion processes. These results might prove most interesting for conservators and curators as they provide them with relevant information to help properly select the appropriate conservation/restoration treatment. Therefore, choice of coins was characterised by them having a thin natural patina formed in an atmospheric environment because this thin patina is apt for the surface analysis techniques explored herein, particularly the novel FIB-FESEM-EDX technique. The artifacts conserved in buried and submarine environments generally exhibit thick corrosion layers, with thicknesses of several hundreds of $\mu \mathrm{m}$ that are not apt for the surface analysis techniques used herein. In most cases, the study of these objects implies drastic sampling methods, such as cutting coins to study corrosion layers, which involves removing large samples, in the order of $1 / 4$ of a coin, to obtain representative cross-sections of the patina and the coin core material [7], or to apply drastic irreversible treatments done with chemical products that attack coins by removing the corrosion layer and, thus, analysing the non-corroded core [36]. These treatments 
imply severely damaging the object. For this reason, ancient coins from archaeological sites, where coins were subjected to burial or submarine environments, were discarded.

As a second criterion, a set of coins was selected by scanning the three last centuries to study possible changes in the characteristics of the thin natural patina formed concomitantly with changes in the composition of the blank alloy that took place during successive centuries.

The third criterion was to study possible variations in the composition of the thin patina due to the alloy type used in different countries.

The fourth criterion was to select those coins that had not been previously restored so they conserved the original natural patina. The series of studied coins (Fig. 1) forms part of a private collection that has been inherited from generation to the next. This is the reason why, presumably, all the coins have been exclusively exposed to atmospheric environments during the period when they were in circulation and were conserved by the collector. The set of coins includes eight copper-based coins minted in spain, Sovereign Military Order of Malta, France and the UK from 1709 to 1924. The description and main characteristics of these coins are summarised in Table 1 .

\subsection{Instrumentation}

Microscopy images of coins were acquired by a Leica M165 stereo microscope using a high-resolution digital image capture system IC80HD controlled by the LAS software.

The surface analysis runs to characterise the micromorphology and elemental composition of the corrosion layers formed on the series of coins was carried out by performing trenches using a field emission scanning electron microscope coupled to a focused ion beam Zeiss (Orsay Physics Kleindiek Oxford Instruments), model Auriga compact equipment. The operating conditions were: voltage, $30 \mathrm{kV}$ and current intensity, $500 \mu \mathrm{A}$ and $20 \mathrm{nA}$ in FIB to generate the focused beam of $\mathrm{Ga}$ ions and a voltage of $3 \mathrm{kV}$ in FESEM. The Ga beam impacts perpendicularly on the plane of the vertical wall of 
the trench by tilting the stage $54^{\circ}$ where the coin is placed. A voltage of $3 \mathrm{kV}$ was used in FESEM to acquire electron images. An energy dispersive X-ray microanalysis was performed in trenches with an Oxford-X Max system coupled to FESEM, which was controlled by the Aztec software. A voltage of $20 \mathrm{kV}$ and a working distance of 6-7 $\mathrm{mm}$ were applied. The ZAF method was followed to correct the interelemental effects in the semiquantitative microanalysis. A counting time of $100 \mathrm{~s}$ was used. The secondary and backscattered electron images and X-ray spectra were obtained in cross-sections. The latter were acquired in the spot, area and linescan mode. This last method provided deep profiles of the element content.

The first criterion for selecting the trench dimensions was that they were not seen by the naked eye, and by even using a low-magnification optical microscope. This is the main requirement that cultural heritage stakeholders establish mandatorily to authorise the analysis of an archaeological or museum piece. Fig. 2 depicts a trench of (15x15) $\mu$ m. The dimensions selected in the present work accomplish these requirements and enable the study of atmospheric corrosion layers that fall within the range of only a few $\mu$ m so that it is also possible to analyse the upper part of the uncorroded core of a coin.

The criterion for selecting the points to perform trenches in each coin consisted of making two randomly chosen replicates of trenches, in both the obverse and reverse, on the more exposed parts of coins (devices) on which the corrosion layer was extremely thin. In parallel, two other trench replicates were performed in the field of the coin where the corrosion layer exhibited deposits and a thicker corrosion layer.

The IR absorption spectra of the microsamples scraped from the surface of coins were obtained in the attenuated total reflectance (ATR) mode using a Vertex 70 Fourier-transform infrared spectrometer with an FR-DTGS (fast recovery deuterated triglycine sulphate) temperature-stabilised coated detector and an MKII Golden Gate Attenuated Total Reflectance (ATR) accessory. Thirty-two scans were collected at a resolution of $4 \mathrm{~cm}^{-1}$ and the acquired spectra were processed by the OPUS/IR software.

Electrochemical measurements were taken in a threeelectrode cell using a CH I660C device (Cambria Scientific, Llwynhendy, Llanelli, Wales, UK) at 298 K. Air-saturated aqueous $0.25 \mathrm{M}$ sodium acetate buffer (Panreac), pH 4.75, was used as an electrolyte. In order to avoid any 
contamination associated with the metal ions eventually released to the solution during the electrochemical turnovers, the electrolyte was renewed after each electrochemical run. A sample-modified graphite electrode (Faber Castell TK $9071 \mathrm{H}$ ) was used as the work electrode. A platinum wire counterelectrode and an $\mathrm{Ag} / \mathrm{AgCl}$ ( $3 \mathrm{M} \mathrm{NaCl}$ ) reference electrode completed the three-electrode arrangement.

Reference materials were prepared by powdering at ca 1-2 $\mathrm{mg}$ of the solid in an agate mortar and pestle. The end of the graphite electrode (diameter $<0.5 \mathrm{~mm}$ ) was softly rubbed over the spot of powdered material so that a few microparticles remained abrasively attached to the electrode surface. Finally, the electrode was rinsed with water to remove ill-adhered particles. The electrode was then immersed in the electrolyte. A similar procedure was used to obtain the sample modified electrodes from coins by rubbing the electrode surface on the coin surface in the areas of interest taking a few ng.

The colorimetric data $\left(L^{*}, a^{*}\right.$ and $b^{*}$ coordinates) of the coins were obtained with a Minolta CM-503i spectrophotometer, an Xe-arc lamp and an Si photodiode detector. Calibration was carried out with a standard white (coordinates Y 95.8; x 0.3167; y 0.3344).

\section{Results and Discussion}

\subsection{Visual appearance}

According to the composition of the alloys employed for minting coins, which were obtained by means of FESEM-EDX (vide infra), the studied series of coins was classified as four main types: type $A$, with coins produced with highpurity copper and small additions of lead or lead and zinc (coins 1, 2 and 4); type B, produced with a brass Cu-Zn binary alloy (coin 6); type C, produced with copper with the addition of pewter (coin 3); type D included coins produced with a Cu-Sn-Zn alloy (coins 5, 7 and 8). Figure $3 a, b$ shows a microphotograph obtained on the obverse of the oldest coins 1 and 2 . In it we can see that the coins exhibit a primary reddish patina of cuprite (vide infra), which was more visible in the features pressed onto the 
coin (devices, inscriptions, rim, date, etc.). A secondary black patina, consisting mainly of tenorite, is also observed in the field. Similar micromorphology was observed in coin 4. Figure $3 \mathrm{c}$ shows details of the surface of coin 3 on which a secondary tenorite patina is present in the devices, whereas a thick layer of greyish mineral deposits abundantly fills the field. Details of the surface of coin 6 are shown in Figure 3d. The characteristic yellow-reddish colour of this brass coin and the presence of a secondary blue-greenish patina in the niches formed on the boundary between the background surface and the protruding inscriptions, devices, etc., are remarkable. Figure $3 e$ shows detail of the surface of coin 5 in which the primary cuprite patina is covered by a thin secondary tenorite patina that darkens the coin's reddish colour, mainly in the field. Coin 7 presented similar characteristics. A microphotograph of coin 8 is shown in Figure $3 f$. On this coin, the primary reddish cuprite patina predominates.

The micromorphological characteristics observed by OM agree with the visual appearance to the naked eye, as shown in Figure 4, where diagram $b^{*}$ VS. $a^{*}$ is depicted. Coin 3 of type $C$, which exhibits abundant greyish mineral deposits in the field and a black patina in devices, is placed nearer the origin of the coordinates, followed by older coins of type A, which also have thick secondary dark patinas. Coins 5 and 7, made with Cu-Sn-Zn alloys, are placed close to those of type $A$ and have higher $a^{*}$ and $b^{*}$ values according to their thinner dark patina. Finally, the more recently minted coins 6 and 8 present the highest $a^{*}$ and $b^{*}$ values, which is concomitant with the characteristic reddish colour of the cuprite primary patina that is prevalent in both coins. The different composition of alloys (brass for coin 6 and a Cu-Sn-Zn alloy for coin 8) justifies their different positions in the $b^{*} \mathrm{Vs} a^{*}$ diagram, where the former is distinguishable for the characteristic yellow hue of brass [37].

3.2. Micromorphology and elemental composition of corrosion layers

Figures $5 \mathrm{a}-\mathrm{c}$ and 6 show the secondary and backscattered electron images of the cross-sections obtained by FIB in type A coins 1, 2 and 4. The typical granular morphology of 
copper is discernible in the core of coin 4, shown in Figure 5a. The thickness of the thin corrosion layer that has formed lies between 0.15 and $2.2 \mu \mathrm{m}$. Figure 5b shows details of the advanced intergranular corrosion stage, exhibited by the metal on this layer. Abundant pores, whose size is a few hundred nanometers, are observed in the metal core close to the boundary with the corrosion layer. The deep profiles obtained by FESEM-EDX along the corrosion layer and the metal core for $\mathrm{Cu}, \mathrm{C}, \mathrm{Cl}, \mathrm{Al}, \mathrm{Si}, \mathrm{S}$ and $\mathrm{O}$ were obtained in this trench (Fig. 7). The Cu content in the metal core is about 97\% at the bottom of the trench until $2 \mu \mathrm{m}$ before decreasing alongside the corrosion layer until 65.5\% (Fig. 7a). Conversely, the content of the other elements decreases from the surface to the core boundary. $\mathrm{Ca}, \mathrm{K}$ and $\mathrm{S}$ can be detected until a depth of $650 \mathrm{~nm}, \mathrm{Si}$ and Al until a depth of $1.3 \mu \mathrm{m}, \mathrm{Cl}$ and $\mathrm{O}$ until a depth of 1.9 $\mu \mathrm{m}$, and $\mathrm{C}$ until a depth of $5.8 \mu \mathrm{m}(\mathrm{Fig} .7 \mathrm{C}, \mathrm{b})$. $\mathrm{Pb}$ is found only in the outer spot (1) performed on the coin's surface. The X-ray spectra acquired in the spots (1, 2) and area (3) marked in the photograph (Fig. 5b) confirm these results (see Table 2).

Figure $5 \mathrm{c}$ shows the secondary electron image obtained in the cross-section performed with FIB in coin 2. Most of the surface appears unaltered but, similarly to coin 4, a thin corrosion layer of ca $2.6 \mu \mathrm{m}$ thick, and with abundant intergranular corrosion and infiltrated organic matter (spot 2), is observed in the right upper corner of the trench. The granular metal morphology is discernible in the unaltered copper core. The chemical compositions in the analysed spots and areas are listed in Table 2.

The secondary and backscattered electron images of trench $A$ performed in the device of coin 1, where a thin corrosion layer is found, are shown in Figure $6 \mathrm{a}$ and Figure 6c, respectively. Trench B performed in the field, where a thicker corrosion layer has formed, is shown in Figure 6b and Figure 6d, respectively. Intergranular corrosion, similar to that in coins 2 and 4 , is found in former trench A (thickness ranging between 2-5 $\mu \mathrm{m}$ ). The fact that lead has been added to the copper of the blank to produce this coin is evidenced by the presence of this element in the spots performed in different zones of both trenches (Table $3)$. It suggests that the corrosion processes which induce 
this minor element to outwardly migrate have largely occurred. It should be noted that lead is identified in interstitial zone 2 of trench $A$, rich in organic matter, which suggests that the $\mathrm{Pb}$ (II) ions released from the alloy as a result of corrosion processes have formed metalcarboxylate complexes with infiltrated lipid materials like copper ions (vide infra). The thicker trench B exhibits a more complex morphology with wide fissures in parallel with and transversal to the surface, and advanced intergranular corrosion combined with nanoporous features that seem to have formed as a result of corrosion processes. The elemental compositions found in this trench reflect this complex structure. The $\mathrm{Cu}$ content does not exceed 57\% in lower trench areas, which indicates that the corrosion layer prolongs beyond the limit of the trench. The presence of exogenous elements, such as $\mathrm{Al}, \mathrm{Si}, \mathrm{P}, \mathrm{Ca}, \mathrm{K}$, and $\mathrm{Fe}$, is also remarkable, and should be associated with the clayey and apatitic minerals deposited on the surface, while cl and $S$ should be ascribed to the sulphate and chloride/hydroxychloride minerals that formed as a result of corrosion processes (Table 3). The high Ca content suggests an abundance of calcareous minerals.

Figure 5d shows the secondary electron image of the FIB cross-section taken on coin 6 (type B). The boundary between the unaltered metal core and the corrosion layer is clearly delimitated by a wide fissure that runs in parallel to the surface, formed at a depth of $4 \mu \mathrm{m}$. Abundant intergranular corrosion is observed on the corrosion layer with most interstices and microfissures filled with exogenous materials. A thin metal-rich lamina (ca $250 \mathrm{~nm}$ thick) delimitates the 2 m-thick corrosion layer. Beneath the fissure, the metal core shows an incipient alteration with abundant nanopores that determine the progress of corrosion mechanisms inside the metal core. The elemental compositions measured in different trench regions (spots and area 1-5) are summarised in Table 2. The element contents for $\mathrm{Cu}$ (89.5\%) and $\mathrm{Zn} \mathrm{(7.4 \% ),} \mathrm{obtained} \mathrm{in} \mathrm{the}$ metal core (area 5), indicate that this coin was made with a brass alloy. The $\mathrm{Cu}$ content lowers from a $\mathrm{Cu} / \mathrm{Zn}$ mass ratio of 12 at the bottom of the trench (area 5) to the value 4.5 found on the outer surface of the metal core (spot 4). This result indicates that $\mathrm{Cu}$-depletion has taken place as a consequence of the early corrosion processes 
near the fissure. Some exogenous elements, such as C, O, S and $\mathrm{Ca}$, are also detected here, which evidence how the corrosion mechanisms advance inside the coin. The metalrich lamina at the bottom of the corrosion layer over the transversal fissure (spot 3 ) has a similar composition to that found in the altered upper metal core region 4 . The $\mathrm{X}-$ ray spectra acquired in the metallic grains of the corrosion layer (spots 1 and 2) confirm the more advanced metal degradation noted here. The presence of $\mathrm{Cl}, \mathrm{C}$ and $\mathrm{O}$ is associated mainly with copper oxides, hydroxychlorides and $\mathrm{Cu}$ and $\mathrm{Zn}$ carboxylate complexes. The higher $\mathrm{C}$ and $\mathrm{O}$ contents found in region 2 agree with the organic composition of this interstitial area of the corrosion layer.

Figure $8 \mathrm{a}, \mathrm{b}$ show the backscattered electron images of the FIB cross-sections obtained in coin 3. In trench A (Fig. 8a), a number of grains can be seen whose size is only a few $\mu$ with an irregular shape dispersed in the copper matrix. The X-ray microanalysis confirmed that these grains contain Sb, accompanied by $\mathrm{Cu}$, Sn and Pb (spot 2) (Table 3). These Sb-rich phases are associated with pewter, a Cu$\mathrm{Sb}-\mathrm{Sn}-\mathrm{Pb}$ alloy commonly employed in mints to improve the malleability of the blank [37]. Other exogenous elements, such as $\mathrm{C}, \mathrm{O}, \mathrm{K}, \mathrm{Si}, \mathrm{Ca}$ and $\mathrm{Cl}$, are identified on the outer copper matrix (spot 1). The copper content is depleted along the trench from 98.6\%, (spot 3) to 81\% (spot 1). In Figure $8 \mathrm{~b}$ an angular grain of silica inserted into the blank is seen (area 2). This grain was probably fixed abrasively to the blank during the sand-blast trial undergone by pieces while being minted. Interestingly, an irregular Ag-rich grain is embedded in the former. The FESEM-EDX analysis confirmed the silica grain composition (area 2) and the silver-rich grain (spot 1). Regarding Ag being present, it has been reported that in the $16^{\text {th }}$ and 17th centuries, Spanish Kingdoms had serious problems with counterfeiting copper coins, such as the maravedis [2,38,39], and kings like Felipe IV ordered silver to be introduced into the coinage of copper coins. No pragmatic was issued by Carlos IV about adding silver to copper coins. Therefore, the presence of silver in the studied coin is associated rather with the usual practice of melting old coins down and minting this material containing silver into new maravedís [40]. 
The trenches obtained in type-D coins 5, 7 and 8 are shown in Figure $9 a-d$. The 5 m-thick corrosion layer on coin 5 (Fig. 9a) presents isolated pores and an intergranular morphology on the boundary with the unaltered core. The elemental composition at different depths is summarised in Table 4. The metal core at the bottom of the trench is composed of $\mathrm{Cu}$ and $\mathrm{Sn}$ (area 4). C and O contents progressively decrease from the surface (spot 1 ) to the boundary with the unaltered core (spots 2 and 3), whereas the $\mathrm{Cl}$ content seems to increase. Other exogenous elements, such as Si, $\mathrm{P}, \mathrm{S}, \mathrm{Ca}$ and $\mathrm{Mg}$, are found on the coin's surface together with Zn (spot 1 ). The trench made in the youngest coin 8 (Fig. 9b) reveals the apparent absence of a corrosion layer. Nevertheless, the elemental composition provided by FESEM-EDX at different depths suggests that Zndepletion takes place from the bottom of the trench (Table 4). Finally, the FIB cross-sections obtained in coin 7 are shown in Fig. 9c, d. Trench A, shown in Fig. 9c, was performed in a device area. Here the corrosion layer's thickness ranges between 1-2.5 $\mu \mathrm{m}$ and it exhibits characteristic intergranular corrosion with interstices filled with exogenous materials and corrosion products. Trench B, shown in Fig. 9d, was made on the boundary between the field and the device, where exogenous materials are deposited and corrosion mechanisms progress quickly so that the corrosion layer thickness increases to $12.5 \mu \mathrm{m}$. The elemental composition indicates that this coin was also produced with a ternary Cu-Sn-Zn alloy (Table 4). Cl is the exogenous element found in a higher proportion on both corrosion layers.

\subsection{Identification of corrosion products}

\subsubsection{Voltammetry of immobilised microparticles}

Presence of cuprite, tenorite, copper trihydroxychlorides and lead salts in the studied series of coins was evidenced by VIMPS. By way of example, the square wave voltammogram, obtained in a sample of coin 1, is shown in Figure 10a. The signals at $-0.10 \mathrm{~V}$ and $-0.35 \mathrm{~V}$ are attributable to the reduction in $\mathrm{Cu}$ (I) present in cuprite (Eq. 1) and $\mathrm{Cu}$ (II) from tenorite (Eq. 2) to copper metal, respectively: 


$$
\mathrm{Cu}_{2} \mathrm{O}(\mathrm{s})+2 \mathrm{H}^{+}(\mathrm{aq})+2 \mathrm{e}^{-} \rightarrow 2 \mathrm{Cu}(\mathrm{s})+\mathrm{H}_{2} \mathrm{O}
$$

$$
\mathrm{CuO}(\mathrm{s})+2 \mathrm{H}^{+}(\mathrm{aq})+2 \mathrm{e}^{-} \rightarrow \mathrm{Cu}(\mathrm{s})+\mathrm{H}_{2} \mathrm{O}
$$

The new peak that appears at $-0.45 \mathrm{~V}$ in this voltammogram is attributed to the reduction from $\mathrm{Pb}$ (II) to $\mathrm{Pb}$.

The voltammogram obtained in a sample from coin 8 (Fig. 10b) shows the same features as those of coin 1 for both cuprite and tenorite. The shoulder at $-0.20 \mathrm{~V}$ is associated with the reduction of $\mathrm{Cu}(\mathrm{II})$ to copper trihydroxychlorides according to the process described in Equation (3):

$$
\mathrm{Cu}_{2}(\mathrm{OH})_{3} \mathrm{Cl}(\mathrm{s})+3 \mathrm{H}^{+}(\mathrm{aq})+2 \mathrm{e}^{-} \rightarrow 2 \mathrm{Cu}(\mathrm{s})+\mathrm{Cl}^{-}(\mathrm{aq})+3 \mathrm{H}_{2} \mathrm{O}
$$

\subsubsection{FTIR spectroscopy}

A series of microsamples from the materials constituting the external deposits and corrosion layers of coins were excised with the help of a scalpel under the microscope to analyse by FTIR in the ATR mode. Table 5 summarises the main compounds identified with a qualitative indication of the relative intensity of the IR absorption bands that appear in the IR spectra. Calcite and clayey minerals are present in coins $1-7$ as materials that have been deposited and abrasively fixed to the coin's surfaces. Deposits of calcite and clayey minerals are abundant in coin 3, as shown in Figure 3c, and as confirmed by the intense absorption bands in its IR spectrum in Figure 11a. Interestingly, coin 3 exhibits a $v_{3}$ stretching band of the carbonate group at $1,420 \mathrm{~cm}^{-1}$, whereas this band occurs at $1,405 \mathrm{~cm}^{-1}$ in the other coins. The redshift of this band in most coins is associated with the presence of calcite in an amorphous state that came from microparticulate atmospheric matter [42]. In contrast, the higher crystallinity of the calcite deposits found in coin 3 may be tentatively associated with a burial environment to which this coin could have been exposed during its history. An IR band below $600 \mathrm{~cm}^{-1}$, characteristic of copper oxides cuprite or tenorite and of polymorphs atacamite/clinoatacamite, appears in all the coins to different extents. 
The FTIR analysis also enabled the identification of a series of organic compounds present on the corrosion layers of coins. Lipids are identified by the characteristic stretching vibrations of groups methyl and methylene between 2,960 and 2,850 $\mathrm{cm}^{-1}$, and by the stretching vibration of carbonyl of the ester group at $1,738 \mathrm{~cm}^{-1}$. The presence of lipids on coins' surfaces is associated with the contamination that took place when coins were in circulation and/or with further manipulations of the collector. The stretching vibration of the carboxyl group at $1,704 \mathrm{~cm}^{-1}$ is related to the partial hydrolysis of the triacylglycerols of lipids, from which free saturated longchain fatty acids (palmitic and stearic acid) are released. It has been reported that this process frequently takes place in paintings as a result of the natural ageing of oil paint films, where the drying oil is exposed directly to light and humidity [42]. Therefore, the thin lipid film fixed to coins' surfaces, and exposed to an atmospheric environment, could undergo this same alteration process. Metal oxalates were found in coins 2 and 4-7, depending on their composition. These compounds are characterised by the stretching vibrations of the carboxylate group at 1,643 $\mathrm{cm}^{-1}$ (asymmetric) and 1,360 and $1,320 \mathrm{~cm}^{-1}$ (symmetric) (Fig. 11b). Whereas copper and lead oxalate exhibit two bands at 1,360 and 1,320 $\mathrm{cm}^{-1}$, calcium oxalate exhibits a single band at $1,320 \mathrm{~cm}^{-1}[43,44]$. Copper and lead oxalates have been associated with the decomposition of organic compounds (lipids or proteins) in the presence of copper pigments $[43,44]$, whereas calcium oxalates, mainly the calcium oxalate monohydrate whewellite, are formed in the presence of Ca-containing minerals, such as calcite or gypsum [45], and are frequently found in historic stone monuments and rocks left outdoors [46-48]. The metal-carboxylate complexes that present stretching vibrations within the range of $1,500-1,600 \mathrm{~cm}^{-1}$ were identified on the corrosion layer of coins according to their composition. Ca and $\mathrm{Cu}$ complexes were found in all the coins, with $\mathrm{Pb}$ complexes in coins 1-4 (Fig. 11C) and Zn-complexes in coins 5-8 (Fig. 11b). The metal complexes formed with long saturated fatty acids and amino acids have been frequently found in aged oil [44,49-51] and tempera [52,53] paintings. Metalcarboxylate complexes are formed from the hydrolysed fatty 
acids and metal ions released from coins due to corrosion processes advancing. Thus, an ionomeric phase forms from which metal complexes are precipitated $[54,55]$.

\section{Conclusions}

This study, carried out on a series of analysed coins, provides abundant data on the morphology and composition of the corrosion layer and the upper part of the non-corroded core of coins. Due to the micro-/nano-invasive character of the applied techniques, the performed study was limited to the surfaces and subsurfaces of coins and, therefore, the chemical composition of coins could not be provided. Nevertheless, the identification of the main elements composing each coin allowed us to establish the type of alloy employed to produce coins. The obtained results agree with the compositions used to produce copper-based coins during the different historic periods which each one belongs to.

The proposed multi-technique strategy enabled the identification of both inorganic and organic corrosion products and, concomitantly, the elucidation of the main corrosion processes that took place in coins. FIB-FESEM-EDX is an excellent tool to illustrate the micromorphology of the corrosion layers and the upper part of the unaltered core of coins as it identifies both exogenous and alloyforming elements that migrate inside/outside. VIMP confirmed the presence, to a greater or lesser extent, of cuprite, tenorite and copper trihydroxychlorides as the main corrosion products that make up the corrosion layer. FTIR spectroscopy is a useful technique for characterising minerals, such as the calcite or clayey minerals deposited on coins' surfaces as a result of their use. The identification of free saturated long-chain fatty acids, copper lead and calcium oxalates and metal-carboxylate complexes ( $\mathrm{Cu}, \mathrm{Pb}, \mathrm{Zn}$ and $\mathrm{Ca})$, which have formed on coins' surfaces as a result of mechanisms, is most interesting because they have been frequently reported for historical monuments and old paintings due to the degradation of lipids and their interaction with the metal ions released on the corrosion layer. All these results agree with the visual appearance of the coins characterised by OM and 
colorimetry. The obtained results are valuable for establishing the most suitable conservation treatment for coins.

\section{References}

[1] J. Corsi, F. Grazzi, A. Lo Giudice, A. Re, A. Scherillo, D. Angelici, S. Allegretti, F. Barello, Compositional and microstructural characterization of Celtic silver coins from northern Italy using neutron diffraction analysis, Microchem. J. 126 (2016) 501-508.

[2] A. Doménech-Carbó, M.T. Doménech-Carbó, C. Álvarez-Romero, N. Montoya, T. Pasíes-Oviedo, M. Buendía, Electrochemical Characterization of Coinage Techniques the 17th Century: The maravedís Case, Electroanalysis 29 (2017) 2008-2018.

[3] G.M. Ingo, S. Balbi, T. de Caro, I. Fragalà, C. Riccucci, G. Bultrini, Microchemical investigation of Greek and Roman silver and gold plated coins: coating techniques and corrosion mechanisms, Appl. Phys. A 83 (2006) 623-629.

[4] A. Deraisme, L. Beck, F. Pilon, J.-N. Barrandon, A study of the silvering process of the galloroman coins forged during the third century AD, Archaeometry 48 (2006) 469480 .

[5] F. Rizzo, G.P. Cirrone, G. Cuttone, A. Esposito, S. Garraffo, G. Pappalardo, L. Pappalardo, F.P. Romano, S. Russo, Non-destructive determination of the silver content in Roman coins (nummi), dated to 308-311 A.D., by the combined use of PIXE-alpha, XRF and DPAA techniques, Microchem. J. 97 (2011) 286-290.

[6] M.T. Doménech-Carbó, F. Di Turo, N. Montoya, F. Catalli, A. Doménech-Carbó, C. De Vito, FIB-FESEM and EMPA results on Antoninianus silver coins for manufacturing and corrosion processes, Sci. Reports 8 (2018) 10676.

[7] G.M. Ingo, T. de Caro, G. Padeletti, G. Chiozzini, Microchemical investigation on Renaissance coins minted at Gubbio (Central Italy), Appl. Phys. A 79 (2004) 319-325.

[8] A. Daccà, P. Prati, A. Zucchiatti, F. Lucarelli, P.A. Mandò, G. Gemme, R. Parodi, R. Pera, Combined PIXE and XPS analysis on republican and imperial Roman coins, Nucl. Instum. Methods Phys. Res. B 161-163 (2000) 743-747.

[9] G.M. Ingo, E. Angelini, T. de Caro, G. Bultrini, I. Calliari, Combined use of GDOES, SEM+EDS, XRD and OM for the microchemical study of the corrosion products on archaeological bronzes, Appl. Phys. A 79 (2004) 199-203.

[10] G.M. Ingo, T. de Caro, C. Riccucci, E. Angelini, S. Grassini, S. Balbi, P. Bernardini, D. Salvi, L. Bousselmi, A. C,Ilingiroglu, M. Gener, V.K. Gouda, O. Al 
Jarrah, S. Khosroff, Z. Mahdjoub, Z. Al Saad, W. El-Saddik, P. Vassiliou, Large scale investigation of chemical composition, structure and corrosion mechanism of bronze archeological artefacts from Mediterranean basin, Appl. Phys. A 83 (2006) 513-520.

[11] L. He, J. Liang, X. Zhao, B. Jiang, Corrosion behavior and morphological features of archeological bronze coins from ancient China, Microchem. J. 99 (2011) 203-212.

[12] G. Bertolotti, D. Bersani, P. P. Lottici, M. Alesiani, T. Malcherek, J. Schlüter, Micro-Raman study of copper hydroxychlorides and other corrosion products of bronze samples mimicking archaeological coins, Anal. Bioanal. Chem. 402 (2012) 1451-1457.

[13] J.M. del Hoyo-Meléndez, P. Swit, M. Matosz, M. Wozniak, A. Klisinska-Kopacz, L. Bratasz, Micro-XRF analysis of silver coins from medieval Poland, Nucl. Instrum. and Methods Phys. Res. B 349 (2015) 6-16.

[14] K. Uhlir, R. Padilla-Alvarez, A. Migliori, A.G. Karydas, I. Božičević Mihalić, M. Jakšić, I. Zamboni, R. Lehmann, M. Stelter, M. Griesser, N. Schindel, M. Alram, The mystery of mercury-layers on ancient coins-A multianalytical study on the Sasanian coins under the Reign of Khusro II, Microchem. J. 125 (2016) 159-169.

[15] Shikha Awasthi, Rohit Kumar, G.K.Rai, A.K.Rai, Study of archaeological coins of different dynasties using LIBS coupled with multivariateanalysis, Opt. Lasers Engineering 79 (2016) 29-38.

[16] M. Griesser, W. Kockelmann, K. Hradil, R. Traum, New insights into the manufacturing technique and corrosion of high leaded antique bronze coins, Microchem. J. 126 (2016) 181-193.

[17] F.J. Ager, B. Gómez-Tubío, A. Paúl, A. Gómez-Morón, S. Scrivano, I. OrtegaFeliu, M.A. Respaldiza, Combining XRF and GRT for the analysis of ancient silver coins, Microchem. J. 126 (2016) 149-154.

[18] R. Borges, L. Alves, R.J.C. Silva, M.F. Araújo, A. Candeias, V. Corregidor, P. Valério, P. Barrulas, Investigation of surface silver enrichment in ancient high silver alloys by PIXE, EDXRF, LA-ICP-MS and SEM-EDS, Microchem. J. 131 (2017) 103111.

[19] A. Inberg, D. Ashkenazi, M. Cohen, N. Iddan, D. Cvikel, Corrosion products and microstructure of copper alloy coins from the Byzantine-period Ma'agan Mikhael B shipwreck, Israel, Microchem. J. 143 (2018) 400-409.

[20] M. Crosera, E. Baracchini, E. Prenesti, A. Giacomello, B. Callegher, P. Oliveri, G. Adami, Elemental characterization of surface and bulk of copper-based coins from the 
Byzantine-period by means of spectroscopic techniques, Microchem. J. 147 (2019) 422428.

[21] F. Scholz, B. Meyer, Voltammetry of solid microparticles immobilized on electrode surfaces, Electroanalytical Chemistry, A Series of Advances. J.A. Bard, I. Rubinstein, Eds., Marcel Dekker, New York, vol. 20, 1998, pp. 1-86.

[22] F. Scholz F, U. Schröder, R. Gulaboski, A. Doménech-Carbó Electrochemistry of Immobilized Particles and Droplets, $2^{\text {nd }}$ Edition Springer, Berlin-Heidelberg, 2014.

[23] A. Doménech-Carbó, J. Labuda, F. Scholz, Electroanalytical chemistry for the analysis of solids: characterization and classification (IUPAC Technical Report), Pure Appl. Chem. 85 (2013) 609-631.

[24] A. Doménech, M.T. Doménech-Carbó, I. Martinez-Lazaro, Electrochemical identification of bronze corrosion products in archaeological artefacts. A case study, Mikrochim. Acta, 162 (2008) 351-359.

[25] D. Satovíc, S. Martinez, A. Bobrowski, Electrochemical identification of corrosion products on historical and archaeological bronzes using the voltammetry of microparticles attached to a carbon paste electrode, Talanta 81 (2010) 1760-1765.

[26] A. Doménech, M.T. Doménech-Carbó, T. Pasies, M.C. Bouzas, Application of Modified Tafel Analysis to the Identification of Corrosion Products on Archaeological Metals Using Voltammetry of Microparticles, Electroanalysis 23 (2011) 2803-2812.

[27] A. Doménech-Carbó, M.T. Doménech-Carbó, T. Pasies, M.C. Bouzas, Modeling corrosion of archaeological silver-copper coins using the voltammetry of immobilized particles, Electroanalysis 24 (2012) 1945-1955.

[28] A. Doménech-Carbó, M.T. Doménech-Carbó, J Redondo-MarugáN, L. OseteCortina, M.V. Vivancos-Ramón, Electrochemical characterization of corrosion products in leaded bronze sculptures considering ohmic drop effects on Tafel analysis, Electroanalysis 28 (2016) 833-845.

[29] J. Redondo-Marugán, J. Piquero-Cilla, M.T. Doménech-Carbó, B. Ramirez-Barat, W. Al Sekhaneh, S. Capelo, A. Doménech-Carbó, Characterizing archaeological bronze corrosion products intersecting electrochemical impedance measurements with voltammetry of immobilized particles, Electrochim. Acta 246 (2017) 269-279.

[30] L. Fabrizi, F. Di Turo, L. Medeghini, M. Di Fazio, F. Catalli, Caterina De Vito, The application of non-destructive techniques for the study of corrosion patinas of ten Roman silver coins: The case of the medieval Grosso Romanino, Microchem. J. 145 (2019) 419-427. 
[31] M. Di Fazio, F. Di Turo, L. Medeghini, L. Fabrizi, F. Catalli, C. De Vito, New insights on medieval Provisini silver coins by a combination of nondestructive and micro-invasive techniques, Microchem. J. 144 (2019) 309-318.

[32] A. Doménech-Carbó, M.T. Doménech-Carbó, S. Capelo, T. Pasíes-Oviedo, I. Martínez-Lázaro, Dating archaeological copper/bronze artifacts by using the voltammetry of microparticles, Angew. Chem.Int. Ed. 53 (2014) 9262-9266.

[33] A. Doménech-Carbó, M.T. Doménech-Carbó, J. Redondo-Marugán, L. OseteCortina, J. Barrio, A. Fuentes, M.V. Vivancos-Ramón, W. Al-Sekkaneh, B. Martínez, I Martínez-Lázaro, T. Pasies-Oviedo, Electrochemical characterization and dating of archaeological leaded bronze objects using the voltammetry of immobilized particles, Archaeometry 60 (2018) 308-324.

[34] F. Di Turo, N. Montoya, J. Piquero-Cilla, C. De Vito, F. Coletti, G. Favero, M.T. Doménech-Carbó, A. Doménech-Carbó, Dating Archaeological Strata in the Magna Mater Temple Using Solid-state Voltammetric Analysis of Leaded Bronze Coins, Electroanalysis 30 (2018) $361-370$.

[35] A. Doménech-Carbó, M.T. Doménech-Carbó, E. Montagna, C. Álvarez-Romero, Y. Lee, Electrochemical discrimination of mints: The last Chinese emperors Kuang Hsü and Hsüan T'ung monetary unification, Talanta 169 (2017) 50-56.

[36] M. Hajivaliei, M.L. Garg, D.K. Handa, K.L. Govil, T. Kakavand, V. Vijayan, K.P. Singh, I.M. Govil, PIXE analysis of ancient Indian coins Methods in Physics Research B 150 (1999) 645-650.

[37] A.M. Tracey-Woodward, The minted ten-cash coins of China, M.R. Fried Ed. Oakland, USA, 1971.

[38] P. Rueda Rodríguez-Vila, R. López Cortés, Presentación de una nueva variante tipológica de ocho maravedís de Felipe IV de ceca Coruña, Omni, 5 (2012) 96-99.

[39] X. Sanahuja-Anguera, Las grandes falsificaciones de vellón castellano en los siglos XVI y XVII, Gaceta Numismática, 184 (2012) 15-29.

[40] J.R. De Francisco Olmos, Propaganda política en la monarquía de los Borbones (1700-1868) in Proceedings of VI Jornadas Científicas sobre Documentación Borbónica en España y América (1700-1868), Ed. Universidad Compluense, Madrid, pp. 177-234.

[41] S. Gunasekaran, G. Anbalagan, S. Pandi, Raman and infrared spectra of carbonates of calcite structure, J. Raman Spectrosc. 37 (2006) 892-899. 
[42] D. Erhardt, C.S. Tumosa, M.F. Mecklenburg, Long-Term Chemical and Physical Processes in Oil Paint Films. Stud. Conserv. 50 (2005) 143-150.

[43] A. Nevin J.L. Melia, I. Osticioli, G. Gautier, M. P. Colombini, The identification of copper oxalates in a 16th century Cypriot exterior wall painting using micro FTIR, micro Raman spectroscopy and Gas Chromatography-Mass Spectrometry, J. Cult. Herit. 9 (2008) 154-161.

[44] N. Salvadó, S. Butí, J. Nicholson, H. Emerich, A. Labrador, T. Pradell Identification of reaction compounds in micrometric layers from gothic paintings using combined SR-XRD and SR-FTIR, Talanta 79 (2009) 419-428.

[45] F. Cariati, L. Rampazzi, L. Toniolo, A. Pozzi, Calcium oxalate films on Stone surfaces: experimental assessment of the chemical formation, Stud. Conserv. 45 (2003) 180-188.

[46] A. Watchman, A review of the history of dating rock varnishes, Earth Sci. Rew. 49 (2000) 261-277.

[47] L. Rampazzi, A. Andreotti, I. Bonaduce, M.P. Colombini, C. Colombo, L. Toniolo, Analytical investigation of calcium oxalate films on marble monuments, Talanta 63 (2004) 967-977.

[48] P. Maravelaki-Kalaitzaki, Black crusts and patinas on Pentelic marble from the Parthenon and Erechtheum (Acropolis, Athens): characterization and origin, Anal. Chim. Acta 532 (2005) 187-198.

[49] R. Mazzeo, S. Prati, M. Quaranta, E. Joseph, E. Kendix, M. Galeotti, Attenuated total reflection micro FTIR characterization of pigment-binder interaction in reconstructed paint films. Anal. Bioanal. Chem. 392 (2008) 65-76.

[50] M.J. Plater, B. De Silva, T. Gelbrich, M.B. Hursthouse, C.L. Higgitt, D.R. Saunders, The characterisation of lead fatty acid soaps in "protrusions" in aged traditional oil paint, Polyhedron 22 (2003) 3171-3179.

[51] L. Robinet, M.C. Corbeil, The Characterization of Metal Soaps. Stud. Conserv. 48 (2003) 23-40.

[52] N.S. Cohen, M. Odlyha, R. Campana, G.M. Foster Dosimetry of paintings: determination of the degree of chemical change in museum exposed test paintings (lead white tempera) by thermal analysis and infrared spectroscopy, Thermochim. Acta 365 (2000) 45-52. 
[53] M. Odlyha, N.S. Cohen, G.M. Foster, R.H. West Dosimetry of paintings: determination of the degree of chemical change in museum exposed test paintings (azurite tempera) by thermal and spectroscopic analysis, Thermochim. Acta 365 (2000) 53-63.

[54] J.J. Hermans, K. Keune, A. van Loon, R.W. Corkery, P.D. Iedema, Ionomer-like structure in mature oil paint binding Media, RSC Adv. 6 (2016) 93363-93363.

[55] J.J. Hermans, K. Keune, A. van Loon, P.D. Iedema, An infrared spectroscopic study of the nature of zinc carboxylates in oil paintings, J. Anal. At. Spectrom. 30 (2015) 1600-1608.

Acknowledgments: Financial support is gratefully acknowledged from the Spanish "R+D+I" project CTQ2017-85317-C2-1-P, CTQ2014-53736-C3-1-P and CTQ201453736-C3-2-P, which are supported by the Ministerio de Ciencia, Innovación y Universidades, Fondo Europeo de Desarrollo Regional (ERDF) funds and Agencia Estatal de Investigación (AEI). The authors wish to thank Mr. Manuel Planes, Dr. José Luis Moya and Mrs. Alicia Nuez Inbernón, technical supervisors of the Electron Microscopy Service of the Universitat Politècnica de València. 
Table 1. List of chronologically ordered coins, including descriptions and main characteristics.

Table 2. The element content obtained by FESEM-EDX in coins 2, 4 (type A) and 6 (type B).

Table 3. The element content obtained by FESEM-EDX in coins 1 (type A) and 3 (type C)

Table 4. The element content obtained by FESEM-EDX in coins 5, 7 and 8 (type D).

Table 5. The IR absorption bands of the compounds found in the series of studied coins. 


\section{Figure captions}

Figure 1. Photographic image of coins.

Figure 2. Secondary electron images of the trench performed in a coin taken on different scales illustrating the character quasi-non-invasive of this technique.

Figure 3. Microphotographs obtained by an optical microscope in: a) coin 1; b) coin 2; c) $\operatorname{coin} 3$; d). coin 6 ; e) coin 5 ; f) coin 8 .

Figure 4. Diagram $b^{*} v s . a^{*}$ of the chromatic coordinates for the series of studied coins.

Figure 5. A secondary electron image obtained in the trenches formed with FIB in: a) coin 4 (type A); b) detail of the previous image; c) coin 2 (type A); d) coin 6 (type B).

Figure 6. Coin 1 (type A). Secondary (a) and backscattered (c) electron images of trench A formed with FIB in an area of the coin with a thin corrosion layer. Secondary (b) and backscattered (d) electron image of trench B formed with FIB in an area of the coin with a thick corrosion layer.

Figure 7. Deep profiles of the elemental content obtained with FESEM-EDX in coin 4 for: a) $\mathrm{Cu}$; b) $\mathrm{C}$; c) $\mathrm{O}, \mathrm{Cl}, \mathrm{S}, \mathrm{Al}$ and $\mathrm{Si}$.

Figure 8. Backscattered electron images obtained in the trenches formed with FIB in coin 3 (type C).

Figure 9. Secondary electron images obtained in the trenches formed with FIB in type D coins: a) coin 5; b) coin 8; c) trench A in coin 7 and d) trench B in coin 7.

Figure 10. Square wave voltammograms (two or three independent replicate experiments) of the samples from: a) coin 1 and b) coin 8; attached to graphite electrodes immersed in air-saturated $0.25 \mathrm{M} \mathrm{HAc} / \mathrm{NaAc}, \mathrm{pH}$ 4.75. Potential scan initiated at $+0.8 \mathrm{~V}$ in the negative direction; potential step increment $4 \mathrm{mV}$; square wave amplitude $25 \mathrm{mV}$; frequency $5 \mathrm{~Hz}$.

Figure 11. IR absorption spectra of: a) coin 3; b) coin 7; c) coin 1: Detail of the 1,500$1,600 \mathrm{~cm}^{-1}$ and $1,500-1,300 \mathrm{~cm}^{-1}$ regions of the metal complexes and the metal-oxalate bands in the insets. A: copper trihydroxychloride polymorphs atacamaite/clinoatacamite; S: clayey minerals; C: calcite; L: lipidic compounds; W: $\mathrm{Cu}$, $\mathrm{Pb}$ and $\mathrm{Ca}$ oxalate (whewellite); $\mathrm{MC}$ : metal-carboxylated complexes; CU/T: cuprite/tenorite. 